\title{
La comprensión de las ironías orales ${ }^{1}$
}

\author{
Understanding verbal ironies
}

\author{
Nina Crespo ${ }^{1}$, Ricardo Benítez ${ }^{2}$, Pablo Cáceres $^{3}$ \\ ${ }^{1}$ Pontificia Universidad Católica de Valparaíso, Instituto de Literatura y Ciencias del Lenguaje, \\ Facultad de Filosofía y Educación, Valparaíso, Chile. \\ e-mail:ncrespo@ucv.cl \\ ${ }^{2}$ Pontificia Universidad Católica de Valparaíso, Instituto de Literatura y Ciencias del Lenguaje, \\ Facultad de Filosofía y Educación, Valparaíso, Chile. \\ e-mail: rbenitez@ucv.cl \\ ${ }^{3}$ Pontificia Universidad Católica de Valparaíso, Facultad de Filosofía y Educación, Valparaíso, Chile. e-mail: \\ pablo@psicometodos.com
}

\begin{abstract}
El presente trabajo informa del desarrollo de la comprensión oral de las ironías en niños y niñas. Se revisan diversas teorías que intentan explicar el procesamiento de ironías y se da cuenta de los más importantes estudios acerca de su desarrollo. Se midió la comprensión en 985 participantes mediante un instrumento interactivo aplicado individualmente, en el cual debían reconocer la interpretación de un tipo en cuatro grupos de edad diferente (5-7, 8-9, $10-11,12-14)$. Los resultados muestran que hay cambios cuantitativos en las edades de los sujetos; que pueden observarse diferencias significativas y que los enunciados contrafactuales parecerían más fáciles de comprender. Se concluye que el desarrollo de la comprensión de la ironía es un fenómeno lento que ocurre en toda la edad escolar y que se ve afectada por el grado de prototipicidad del enunciado (de ironías más prototípicas y contrastivas a menos prototípicas y contrastivas).
\end{abstract}

Palabras clave: comprensión de la ironía, desarrollo tardío, tipo de enunciado, teoría de la mente.

This paper gives an account of the development of understanding verbal ironies by children, measured in 985 participants and using an interactive evaluation instrument applied to each subject. They had to recognize the interpretation of one type of irony. The results show that there are quantitative changes in the age of the subjects, significant differences in four groups of age could be observed (5-7, 8-9, 10-11, 12-14), and non-factual statements seemed easier to understand. We conclude that the development of verbal irony is a slow phenomenon that takes place in all school age and it is affected by the degree of prototype of the statements (from the more prototypical and contrastive ironies to the less prototypical and contrastive ones).

Key words: understanding verbal ironies, delayed development, type of statement, theory of mind. 1. INTRODUCCIÓN

Para comprender enunciados orales, tanto irónicos como no irónicos, es necesario manejar no sólo información lingüística, sino también extralingüística y paralingüística. El receptor debe enfrentarse con lo que proviene de estas tres fuentes de información para poder dar sentido al enunciado que se está llevando a cabo en su presencia. Los significados "de diccionario" que pertenecen al sistema lingüístico y se definen dentro de él sufren transformaciones muy pronunciadas cuando son utilizados en conjunción con los otros factores. Tal vez, ayudada por esta interacción y facilitada -según Chomsky (1998)- por mecanismos innatos, la adquisición de la lengua oral por parte de los niños se produce en forma espontánea a partir más o menos de los dos años, y al entrar al sistema escolar en el cual se concretará la alfabetización, ya pareciera haber logrado un desarrollo bastante funcional (Owens 2003).

No obstante, permanecen ciertos aspectos del lenguaje que parecieran tener su desarrollo durante la edad escolar y la adolescencia (Nippold 1998; Owens 2003). Entre estas adquisiciones tardías se encuentra la capacidad de los niños de comprender las ironías que se producen en la lengua oral.

A partir de allí, el objetivo del presente trabajo es describir el desarrollo de la comprensión oral de enunciados irónicos en niños entre los cinco y los trece años de edad que asisten a colegios municipales, subvencionados y particulares en dos ciudades de Chile. De esta manera, se busca: (a) describir el grado de comprensión de las ironías en las diferentes edades; (b) determinar la presencia de diferencias significativas en la comprensión de ironía respecto a la edad de los participantes, estableciendo las edades críticas en el desarrollo; y c) determinar qué tipo de enunciados irónicos son más fáciles y más difíciles de

\footnotetext{
${ }^{1}$ Financiado por Proyecto FONDECYT No 1040740.
} 
comprender.

\section{COMPRENSIÓN DE LA IRONÍA}

Dentro de la tradición retórica y de la pragmática tradicional, se afirma que con un enunciado irónico el emisor dice algo opuesto a aquello que quiere comunicar (Searle 1993). Esta idea ha producido muchas polémicas (Creusere 1999; Anolli, Infantino \& Ciceri 2001), pues no siempre el emisor de una ironía oral comunica lo contrario de lo que afirma a un interlocutor, presente en un contexto dado. Como señala el ejemplo de Belinchón (1999), una persona podría atacar irónicamente a un pedante que da información no solicitada, diciéndole: "Tú sí que sabes de este tema" con un tono burlón. El emisor no necesariamente está comunicando algo contrario a lo que dice, sino que intenta señalar el poco interés que hay en escucharlo. Tomando en cuenta estas consideraciones, sí es posible destacar la idea de que para la comprensión de una ironía es necesario percibir la determinada actitud del emisor hacia aquello que enuncia y hacia su posible interlocutor, ya sea burla, sarcasmo, indiferencia, etc. (Sperber 1984, Sperber \& Wilson 1998; Anolli, Infantino \& Ciceri 2001).

La ironía oral, además, posee -a diferencia de otras formas de significado no literal, como las peticiones indirectas o las frases hechas-, una caracterización prosódica determinada. Padilla (2005) señala que la entonación de este tipo de enunciado está caracterizada acústicamente por el carácter enfático de la inflexión final de la curva entonativa, es decir, por un aumento de los hercios del rango característico del hablante. Dicha configuración paralingüística pareciera hacer a los enunciados irónicos más fáciles de identificar, aunque su rol en la comprensión ha sido ampliamente debatido en la literatura acerca del tema (Creusere1999) y autores como Keenan y Quigley (1999) señalan que es sólo uno de los elementos que ayudan al reconocimiento e interpretación del enunciado irónico.

2.1. Teorías acerca de la comprensión de la ironía. Para entender adecuadamente el fenómeno de la comprensión del enunciado irónico es necesario considerar las diferentes posturas teóricas que intentan dar cuenta de ella.

Una de estas teorías corresponde a la línea de la llamada Pragmática Estándar (Searle 1993 y Grice 1975), para la cual interpretar una ironía implica comprender la intención de quien la emite. Para ellos, el receptor procesa inicialmente el significado literal del enunciado irónico pero, al ver su inadecuación en el contexto, accede a la interpretación de su significado no literal. Grice (1975) precisaría que el oyente al notar la violación abierta de la Máxima de Cualidad genera una implicatura que contiene el significado apropiado de la ironía.

Jogersen, Miller y Sperber (1984), en su teoría de la Mención Ecoica sostienen que la interpretación de lo irónico se produce porque el hablante le señala al oyente hechos, comentarios, opiniones, expectativas o normas previamente conocidas por ambos; sin embargo, no informa acerca de estas realidades, se las menciona, indicando su actitud hacia las mismas. El significado literal sólo se presenta para llevar al oyente a interpretar cuál es la actitud del que habla respecto de lo que está diciendo y, por tanto, no es procesado en sí mismo. De esta manera, la comprensión se llevaría a cabo en un solo paso y no en dos, como proponían los autores de la pragmática estándar. Kreuz y Glucksberg (1989) reformulan esta propuesta y presentan una Teoría del Recordatorio Ecoico, parecida a la anterior, pero a diferencia de ella da un valor especial al enunciado lingüístico que sirve para recordar o activar información lingüística o extralingüística que comparten los interlocutores.

Proponer que el hablante debe apelar a una cierta información extralingüística que le está siendo señalada es una hipótesis bastante plausible para explicar el procesamiento de lo irónico. Sin embargo, Creusere (1999) señala que la teoría ecoica es demasiado restrictiva, puesto que, en primer lugar, no todas las instancias de ironía implican la mención de un antecedente implícito y, en segundo lugar, intenta dar sólo una explicación alternativa a la manera en que se procesan los actos de habla. Asimismo, existen casos en los cuales el recordatorio ecoico no es tan evidente; Ruiz, Marimón y Timofeeva (2004) señalan que en estos casos cobra más importancia la puesta en juego de factores paralingüísticos y extralingüísticos intencionados (como gestos o posturas corporales).

Otro enfoque explicativo está constituido por la Teoría de la Pretensión o del fingimiento (Clark \& Gerrig 1984), la cual sugiere que la ironía es una forma de acto comunicativo en que un hablante pretende ser una persona imprudente que le habla a una audiencia no iniciada. El modelo de estos investigadores se destaca por su intento de cambiar el foco desde el enunciado a los participantes. Esta teoría está basada en la dramaturgia, en la cual se encuentra el dramaturgo, el público y el personaje, y sostiene la noción de que la ironía es actuación. El hablante pretende ser una persona invisible que se 
dirige a una audiencia desconocida y esto conforma un aire teatral de melodrama (Creusere 1999). Al reconocer la pretensión del hablante, el oyente entiende la actitud negativa de aquél sin procesar el significado literal del enunciado.

De acuerdo a los teóricos de la pretensión (y al igual que los de la mención ecoica), el mensaje literal no necesita ser considerado, puesto que las características de la ironía conducen directamente al reconocimiento de que el hablante está expresando una actitud acerca de la situación: el único significado que debe considerarse es el que implica un enunciado irónico. Clark (1996) señala que en la producción de la ironía ocurren "actos comunicativos escenificados", un grupo que incluye la ironía, el sarcasmo, la hipérbole, la expresión moderada, la broma y las preguntas retóricas. Colston (2002) señala que dichos actos escenificados tienen varias propiedades. Por un lado, permiten destacar el contraste evidente entre lo demostrado (o pretendido) y la situación real y, por otro, este tipo de enunciados es negable, pues el hablante puede negar la interpretación no dicha de tal enunciado. Después de todo, el significado real de la ironía es implícito más que explícito.

La Teoría de la Pretensión permitiría explicar la ironía en función de cierto tipo de información extralingüística relacionada con el interlocutor y con las reglas de interacción misma que surgen en la comunicación lingüística. Sin embargo, esta teoría no deja de tener objeciones. Kreuz y Glucksberg (1989), al referirse al planteo inicial de Clark y Gerrig (1984), indican que esta forma de explicación puede ser demasiado poderosa y demasiado limitada, puesto que la noción de "pretensión" se puede aplicar a todos los actos de habla indirectos (v.g., las peticiones indirectas). Por su parte, Giora (1995) critica la teoría de la pretensión argumentando que ésta no puede explicar en forma adecuada cómo el oyente procesa los actos de habla irónicos, y que considera sólo el significado implicado sin apelar al significado literal.

En un planteamiento que intenta armonizar la teoría de la pretensión con la teoría ecoica, KumonNakamura, Glucksberg y Brown (1995) incorporan aspectos del recordatorio ecoico en su Teoría de la Pretensión Alusiva, cuya intención es dar cuenta de todos los tipos de ironía discursiva. Estos investigadores reconocieron dos aspectos centrales. Un primer aspecto se refiere a que no todos los enunciados irónicos involucran una mención ecoica o recordatorio. Para explicar esto, observaron que la ironía puede ser comunicada en cuatro modos (además de los asertivos contrafactuales): (1) aseveraciones verdaderas, (2) preguntas, (3) ofrecimientos y (4) solicitudes exageradamente amables. Los últimos tres actos parecen ser más alusivos que ecoicos en naturaleza y dichas alusiones a expectativas o normas violadas pueden ser directas o indirectas. Los autores sugieren que el recordatorio ecoico es sólo un tipo de alusión y, por tanto, es más exacto pensar que la alusión a (en oposición a la mención ecoica de) pensamientos, conductas, etc., anteriores es una característica necesaria de los actos de habla irónicos. Un segundo aspecto de esta teoría es la "insinceridad pragmática", o violación de cualquiera de las siguientes condiciones para estructurar los actos de habla correctamente: a) el contenido proposicional de un enunciado, b) el estatus tanto del hablante como del oyente, c) la sinceridad del estado psicológico expresado o implicado por el enunciado y d) la percepción de la sinceridad del hablante por parte del oyente. La insinceridad pragmática es un término utilizado por Kumon-Nakamura et al. (1995) para reemplazar la noción de que toda ironía debía decir necesariamente lo contrario de lo que se intenta comunicar, sostenido por la Pragmática Estándar. El nuevo concepto es más amplio y permite ver a la pretensión o fingimiento como una forma de insinceridad pragmática.

Finalmente, Giora $(1995,2003)$ postula la Teoría de la Negación Indirecta, en la cual sostiene que la ironía es una forma de negación donde falta un marcador de negación explícito. Creusere (1999) señala que esta teoría parte desde el supuesto tradicional de que las intenciones de los hablantes irónicos deben comunicar algo diametralmente opuesto a lo que realmente se dice. En este sentido, coincide con lo propuesto por la Pragmática Estándar. Sin embargo, se diferencia de ella porque, mientras Searle (1993) y Grice (1975) consideran que el oyente computa lo literal y salta a lo no literal, para Giora (1995) el oyente computa los dos significados a la vez, y salta a la interpretación más adecuada. Creusere (1999) señala que las dos teorías se caracterizan por utilizar diferentes medios para el mismo fin. Cabe señalar que Giora (2003), en un análisis posterior, admite que el procesamiento de la ironía también estaría relacionado con el grado de destacabilidad cognitiva, o familiaridad que dicho enunciado tendría.

De todas las teorías anteriormente citadas, pareciera que la propuesta por Kumon-Nakamura et al. (1995) es la más completa, ya que logra dar cuenta en forma más detallada de los diversos aspectos que caracterizan a la ironía como fenómeno comunicativo.

2.2. ¿Cómo se desarrolla la capacidad de comprender ironías? Las teorías anteriormente citadas intentan dar cuenta de cómo se produce la comprensión de los enunciados irónicos, pero no llegan a explicar cómo adquieren los niños esta capacidad de interpretar la ironía a través de alguno de estos 
mecanismos, ni tampoco a qué edad se supone que esto ocurre. Creusere (1999) señala la importancia de que existan estudios en los cuales las diversas teorías sirvan para explicar aspectos de la adquisición. Es más, ella misma (Creusere 2000) busca confirmar la teoría de Kumon-Nakamura et al. (1995) de la Pretensión Alusiva y comprueba que los niños de 8 años -al igual que los adultos- son capaces de reconocer tanto la alusión como la insinceridad pragmática en los actos de habla irónicos.

Más allá de estos hallazgos puntuales es necesario entender cuál es el momento de la adquisición lingüística en el cual el niño es capaz de comprender y utilizar la ironía. Nippold (1998) indica que dicha capacidad se desarrolla durante la edad escolar y la adolescencia, es decir, entre los seis y los dieciocho años de edad y, por ello, puede considerarse parte del desarrollo tardío del lenguaje. A partir de allí, el panorama investigativo es también bastante diverso. Nakassis y Snedeker (2002) señalan que por más de veinte años los investigadores han tratado de determinar cuándo los niños comienzan a comprender las ironías, aunque todavía no existe una respuesta clara. Algunos autores como Demorest, Silverstein, Gardner y Winner (1983) sostienen que la comprensión de la ironía emerge en la adolescencia temprana (13 o 14 años). Otros como Ackerman (1986) y Capelli, Nakagawa y Madden (1990) han descubierto evidencias de que la comprensión de los enunciados irónicos se inicia en los primeros años de la edad escolar. Finalmente, Dews, Winner, Kaplan, Rosenblatt, Hunt, Lim, McGovern, Qualter y Smarsh (1996) señalan que la capacidad de comprender ironías emerge entre los cinco y seis años de edad. ¿A qué se debe esta diferencia de opiniones? Ya Creusere (1999) había señalado que esta confusión se debía al uso de materiales y procedimientos distintos y, por su parte, Nakassis y Snedeker (2002) señalan que la ironía no es un fenómeno de todo o nada, sino que constituye un continuum que abarca desde el enunciado más sutil al más explícito, dependiendo de la fuerza de las pistas contextuales disponibles para inferir la intención del hablante. Asimismo, los autores indican que los niños mayores (10 años o más) pueden detectar formas más sutiles de ironía y tener éxito en tareas que requieren recordar elementos esenciales. Por otra parte, aunque los niños pequeños (5 o 6 años) tienen un desempeño peor, de todas formas son capaces de comprender en alguna medida los enunciados irónicos.

Ahora bien, ¿por qué la capacidad de comprender ironías lingüísticas se adquiere en la edad escolar y no antes o después? Puede considerarse que ella depende de la adquisición por parte del niño de habilidades que están más o menos relacionadas con la comprensión del lenguaje. Happe (1993) Sullivan, Winner y Hopfield (1995) sostienen que la ironía se ha atribuido a cambios concomitantes en la teoría de la mente. El término Teoría de la Mente se refiere a la capacidad que posee una persona de predecir y explicar la conducta de otros al darse cuenta de que ella misma y las otras personas poseen estados mentales, tales como creencias e intenciones (Astington 1991). Belinchón, Rivière e Igoa (1992) señalan que los organismos demuestran que poseen teoría de la mente cuando son capaces de engañar (crear falsas creencias en otros) o de reconocer cuándo otro organismo ha sido engañado o trata de engañar. Como capacidad, la teoría de la mente emerge muy tempranamente en la vida del niño; a este respecto, Belinchón et al. (1992) nos refieren la atracción que tienen los niños de dos años por los juegos que implican engañar o ser engañado. Sin embargo, la posibilidad de atribuir creencias erróneas a un tercero recién emerge al inicio de la edad escolar; de esta manera, Wimmer y Perner (1983) demostraron que antes de los cuatro años, ningún niño era capaz de dar cuenta de la situación de engaño a la que era inducida un determinado personaje por un tercero. Los autores concluyen que es entre los 4 y 6 años que emerge esta capacidad de representarse las relaciones entre los estados epistémicos de dos o más personas.

Quien comprende una ironía debe ser consciente de las intenciones del hablante de generar ciertas representaciones mentales en sus interlocutores para poder diferenciarla de la mentira o el engaño; este hecho relacionaría la comprensión de lo irónico con la teoría de la mente. Creusere (1999) reporta que niños de 5 y 6 años confunden las ironías con las mentiras piadosas, tal vez porque esta capacidad de metarrepresentar está todavía estableciéndose. Por su parte, Winner y Leekam (1991) descubrieron que los niños mayores de seis años que fueron capaces de comprender las ironías, también reconocieron la intención de segundo orden de los hablantes irónicos. Una investigación realizada por Sullivan, Winner y Hopfield (1995) confirma lo anterior y concluye que una teoría de la mente de segundo orden, específicamente la habilidad para realizar predicciones de ignorancia, es necesaria para que los niños discriminen entre bromas irónicas y mentiras.

Otro factor importante es el concepto que el niño tiene del lenguaje y, por ende, las estrategias interpretativas que utiliza. Levorato y Cacciari (1992, 1995), sin hablar concretamente de ironía, se refieren a un desarrollo de la competencia figurativa que el escolar logra atravesando una serie de fases. Las autoras señalan que los niños hasta los cinco años parecieran tener una visión referencial del lenguaje y -en concordancia con ella- utilizan estrategias de interpretación literales y lineales (pieza por pieza). 
Esta fase sería superada más adelante y el niño aprendería que si lo dicho no coincide con lo esperado u observado no debe ser considerado un error, sino que debe ser interpretado a partir del conocimiento previo o considerando las intenciones del interlocutor. En este último caso estaría la ironía, en cuya interpretación se involucraría un concepto más sofisticado del lenguaje y la capacidad de adivinar intenciones y estados mentales que le proveería la teoría de la mente.

Finalmente, es necesario señalar, como lo hicieron Kumon-Nakamura et al. (1995), la gran variedad de enunciados que pueden vehiculizar los significados irónicos. Estas diferentes formas no sólo cobran importancia para la interpretación per se, sino que también podrían influenciar el desarrollo de la comprensión irónica. Tal vez, algunas forman se adquieran de una manera más rápida y fácil que otra; sin embargo, esta discusión no está completamente zanjada.

\section{MÉTODO}

3.1. Diseño y variables. De acuerdo con los objetivos al inicio de este trabajo, cabe señalar que este estudio utiliza un diseño ex post facto retrospectivo de diferencia de grupos. Las variables de investigación son la edad de los participantes y la comprensión del tipo de enunciado irónico, ya que persigue demostrar cómo a mayor edad existe un mayor desempeño en la comprensión de la ironía. Además, se intenta dar cuenta de una posible influencia de los distintos tipos de enunciados irónicos en el grado de facilidad o dificultad con que fueron comprendidos.

3.2. Participantes. La muestra está compuesta por 985 niños entre los cinco y los trece años de edad, quienes asisten a establecimientos educacionales municipales (dependientes del Estado), subvencionados (dependientes del Estado y un particular) y particulares (se autofinancian) de dos ciudades chilenas (Valparaíso y La Serena). Estos tres tipos de colegio atienden a alumnos de estratos socioeconómicos distintos (bajo, medio y alto) y se los consideró para reflejar el universo de la educación básica en Chile. El grupo está distribuido en nueve niveles, desde Kinder hasta $8^{\circ}$ año básico, y está conformado por aproximadamente cien participantes en cada nivel. Los criterios de selección fueron: (1) los participantes debían estar cursando el nivel adecuado para su edad y (2) los participantes no debían tener problemas de lenguaje o aprendizaje en alguna instancia de su desarrollo. En la tabla 1 se ilustra la distribución de la muestra y la edad de los participantes:

Tabla 1

Distribución de la muestra y edad de los participantes

\begin{tabular}{|l|c|c|c|c|c|c|c|c|c|}
\hline Curso & Kinder & $1^{\circ} \mathrm{B}$ & $2^{\circ} \mathrm{B}$ & $3^{\circ} \mathrm{B}$ & $4^{\circ} \mathrm{B}$ & $5^{\circ} \mathrm{B}$ & $6^{\circ} \mathrm{B}$ & $7^{\circ} \mathrm{B}$ & $8^{\circ} \mathrm{B}$ \\
\hline $\begin{array}{l}\text { Edad } \\
\text { promedio } \\
\text { en años }\end{array}$ & 5 & 6 & 7 & 8 & 9 & 10 & 11 & 12 & 13 \\
\hline $\begin{array}{l}\text { Porcentaje } \\
\text { de muestra } \\
\text { total }\end{array}$ & 11,16 & 10,96 & 10,35 & 11,06 & 11,26 & 10,96 & 11,57 & 11,87 & 10,76 \\
\hline
\end{tabular}

3.3. Instrumento. El instrumento fue creado con el fin de medir la capacidad de los niños en edad escolar para comprender significados irónicos y se aplicó por igual a la totalidad de la muestra. Es un software interactivo (Bedoya 1997) que incluye un programa de dibujos animados. Cabe señalar que la selección de un programa de este tipo obedeció, por un lado, a las características de los participantes estudiados, ya que, con este tipo de instrumentos, se minimiza el esfuerzo atencional y representacional -especialmente en los más pequeños, es decir, los niños de cinco años. La idea era observar la capacidad de los niños para comprender significados no literales y no de evaluar cómo ellos responden a las dificultades planteadas por el instrumento.

Asimismo, este software fue diseñado para medir la comprensión de enunciados irónicos orales y de carácter focalizado (Ruiz et al. 2004), en los cuales lo linguiístico y lo situacional poseen un valor 
fundamental. Por este motivo, el contexto extralingüístico fue provisto en forma mediática y se cuidó que el registro paralingüístico señalara que se estaba ante una ironía.

Por otro lado, se eligió un software con estas características porque su parcial interactividad permite una mayor libertad al usuario infantil para determinar la información que desea seleccionar. Sin embargo, esta libertad no es total puesto que las alternativas son propuestas al participante por el instrumento. Este formato de selección múltiple se ha utilizado en otras investigaciones de lenguaje figurado (Levorato, Nesi \& Cacciari 2005) y hace más fácil unificar y medir las respuestas cuando se trabaja con una muestra de esta magnitud.

En el software, José, un personaje en dibujo animado, invita al usuario a acompañarlo en un día de su vida a través de diferentes escenas. El niño encuentra estas escenas separadas en tres contextos de interacción: a) la escuela, en la cual José interactúa con una de sus profesoras y con sus compañeros; b) el almuerzo, en el cual José se encuentra con su familia; y c) el partido de fútbol, en el cual José interactúa con varios amigos.

A lo largo de estas escenas, los personajes participan en 40 instancias de diálogo diferentes, en las cuales se producen diversos significados no literales (Belinchón 1999), 13 de ellos identificables como ironías, expresadas con diferentes tipos de enunciados:

a) Tres enunciados contrafactuales: aquéllos en los cuales se dice exactamente lo contrario de lo que se quiere significar, por ejemplo: “iTú, el gran futbolista!” (Frase dicha por un personaje a José, quien ha jugado mal en un partido de fútbol);

b) Cuatro ironías combinadas con hipérboles y metáforas: "Un poco más y llega a la hora de salida" (Frase dicha por la profesora a José que ha llegado tarde a la clase);

c) Un acto de cortesía evidentemente irónico para el contexto: "Muchas gracias" (Frase dicha por un personaje a José cuando éste le ha negado abiertamente el asiento); y

d) Cuatro preguntas que resultan irónicas en un contexto situacional dado: “¿No quieres un poco más? (Frase dicha por José a otro personaje que se ha tomado toda la bebida de la botella).

Una vez escuchado el diálogo entre los personajes, el supuesto receptor del mensaje le pide al participante que le aclare lo que le quisieron decir. El participante que interactúa con el software se comporta como un tercero que oye la conversación y debe elegir entre tres alternativas:

(a) una paráfrasis apropiada del significado figurado;

(b) una repetición literal del enunciado que no da cuenta del significado intencionado; y

(c) un enunciado distractor que tiene alguna relación con la situación contextual en la que se presenta el diálogo.

Estas tres alternativas aparecen ejemplificadas en el Anexo I y están ordenadas de manera diferente en las distintas instancias de diálogo, con el fin de evitar la existencia de un patrón que podría influenciar las respuestas del participante.

Cabe señalar que tanto el lenguaje utilizado en los diálogos como los eventos que sirven de contexto han sido elaborados considerando la cultura chilena y la variación lingüística del español de Chile. Además, este instrumento fue piloteado con niños y niñas chilenos antes de su elaboración definitiva. En este sentido, el IMIP es un instrumento aplicable a la realidad de este país y, de hecho, ha sido aplicado en dos grandes ciudades chilenas (Valparaíso y La Serena) sin que en los participantes se hayan observado problemas de comprensión evidentes.

Por otro lado, el protagonista del instrumento es un niño y no una niña, y éste es un aspecto que puede haber contribuido a la obtención de resultados diferentes al considerar las respuestas de las participantes en el estudio. La influencia del factor género, entonces, debería incluirse en futuras investigaciones en esta área del desarrollo del lenguaje. Sin embargo, en un estudio estadístico, la diferencia entre varones y mujeres no fue significativa.

Además, se estableció que los ítemes del instrumento cuentan con un poder de discriminación suficiente (Cáceres 2005) y la dimensión de ironía y frase hecha metafórica tuvieron un nivel de fiabilidad aceptable, según el coeficiente alfa de Cronbach $(0,81)$. Además, se utilizó el modelo no paramétrico de Mokken (Cáceres y Crespo 2006) de Teoría de Respuesta al Item (Sijtsma \& Molenaar 2002) para evaluar la dimensionalidad del mismo. Los ítemes incluidos definitivamente son los que lograron formar escala; concretamente, de la dimensión ironía quedaron nueve enunciados (tres contrafactuales, tres ironías combinadas con hipérboles o metáforas, un acto de cortesía en contexto 
irónico y dos preguntas).

3.4. Procedimientos. Finalmente, cabe señalar que el instrumento fue aplicado en forma individual a cada participante por entrevistadores específicamente entrenados para esta tarea. El tiempo de aplicación osciló entre treinta minutos (niños mayores, trece años) y cuarenta y cinco minutos (niños más pequeños, cinco años).

\section{RESULTADOS}

4.1. Análisis de diferencias de grupo: edad ironía. Una primera aproximación a los datos, que se presentan a continuación, sugirió aunar los rangos de edad en otros más amplios, dado que las diferencias sólo se presentaban entre algunos rangos de edad. La tabla 2 sólo tiene como fin ilustrativo denotar los resultados iniciales:

Tabla 2

Medias, desviaciones típicas y error estándar de la media para los enunciados irónicos

\begin{tabular}{|c|c|c|c|c|}
\hline Edad & $\mathrm{n}$ & Media & $\begin{array}{c}\text { Desviación } \\
\text { típica }\end{array}$ & $\begin{array}{c}\text { Error estándar } \\
\text { de la media }\end{array}$ \\
\hline 5 & 91 & 2,02 & 1,48 & 0,155 \\
\hline 6 & 103 & 2,22 & 1,52 & 0,150 \\
\hline 7 & 112 & 2,46 & 1,59 & 0,150 \\
\hline 8 & 96 & 3,15 & 1,66 & 0,170 \\
\hline 9 & 115 & 3,76 & 1,85 & 0,172 \\
\hline 10 & 109 & 4,52 & 1,96 & 0,165 \\
\hline 11 & 110 & 5,06 & 1,73 & 0,146 \\
\hline 12 & 120 & 6,06 & 1,60 & 0,131 \\
\hline 13 & 107 & 6,42 & 1,36 & 0,280 \\
\hline 14 & 21 & 6,42 & 1,28 & \\
\hline
\end{tabular}

Ya se vislumbra que las diferencias entre edades adyacentes son muy pequeñas y es posible que no se encuentren diferencias significativas entre los rangos de edades de 5 a 7 años. Sólo a partir de la edad de 8 años parece presentarse un aumento considerable en el grado de comprensión de enunciados irónicos con respecto a las edades previas y algo similar ocurre con los niños de edades iguales o superiores a 10 años. Los resultados sugieren la necesidad de aunar las edades en rangos más amplios, algo que podrá determinarse a partir de las diferencias.

Aplicada una primera prueba estadística de "Kruskal-Wallis" sobre los datos, se pudo determinar cuáles son los grupos homogéneos o que no difieren entre sí, permitiendo construir nuevos rangos de edad, los cuales han sido representados en la tabla 3 de Estadísticos Descriptivos, que se dispone a continuación: 


\begin{tabular}{|c|c|c|c|c|}
\hline Rango de edad & $\mathrm{n}$ & Media & $\begin{array}{c}\text { Desviación } \\
\text { típica }\end{array}$ & $\begin{array}{c}\text { Error estándar } \\
\text { de la media }\end{array}$ \\
\hline 5 a 7 años & 306 & 2,25 & 1,54 & 0,088 \\
\hline 8 a 9 años & 211 & 3,49 & 1,79 & 0,123 \\
\hline 10 a 11 años & 219 & 4,80 & 1,86 & 0,126 \\
\hline 12 a 14 años & 247 & 6,27 & 1,44 & 0,092 \\
\hline
\end{tabular}

Como se observa, entre los distintos rangos de edad se presentan diferencias importantes respecto del grado de comprensión de enunciados irónicos. El grado de comprensión se incrementa. En particular, se observa un progreso muy importante a partir de los 12 años. Por su parte, las desviaciones típicas son semejantes en cada uno de los rangos de edad, lo que denota que los grupos tienen una dispersión similar en torno a sus respectivas medias.

A partir de los grupos establecidos con base en sus rangos de edad, se llevó a cabo la prueba no paramétrica Kruskal-Wallis, para determinar la presencia de diferencias significativas entre dichos grupos. La tabla 4 presenta las sumas de rangos y rangos medios para cada grupo.

Tabla 4

Sumas de rangos y rangos medios

\begin{tabular}{|c|c|c|c|}
\hline Grupos & $\mathrm{n}$ & Suma de Rangos & Rango Medio \\
\hline 5 a 7 años & 306 & 80521,5 & 263,1 \\
\hline 8 a 9 años & 211 & 87778,5 & 416,0 \\
\hline 10 a 11 años & 219 & 127008,5 & 579,9 \\
\hline 12 a 14 años & 247 & 188327,5 & 762,4 \\
\hline
\end{tabular}

Los resultados obtenidos denotan que hay diferencias significativas $\left(\mathrm{H}_{\mathrm{gl}=3}=459,1, \mathrm{p}<0,001\right)$ entre los diferentes grupos de edad con respecto al grado de comprensión de enunciados irónicos. Las comparaciones múltiples a posteriori se obtuvieron mediante la prueba de Dunn, con un nivel de significación de 0,05. El resultado permitió determinar que estas diferencias se presentan entre todos los grupos comparados. Así, los datos apoyan lo sugerido por la investigación en cuanto a que los participantes de mayor edad logran un mayor grado de comprensión de la expresión irónica que aquellos de menor edad. Si se observan las medias obtenidas, el nivel de los niños de 5 a 7 años es bastante bajo y se puede adelantar que no logran comprender enunciados de esta índole. Por otra parte, resulta evidente un nivel creciente de comprensión a mayor edad.

4.2. Análisis de diferencias de comprensión de acuerdo al tipo de enunciado. En el tercer objetivo, se intentó estimar la presencia de diferencias significativas en el grado de comprensión de los enunciados irónicos en función del tipo de enunciado implicado. En el marco teórico se han definido previamente los tipos de enunciados: contrafactuales, hipérboles, preguntas y fórmulas de cortesía 
irónicos en el contexto y se consideraron sus posibles implicaciones diferenciales en el grado de comprensión que adquieren los estudiantes. Como ya quedó especificado en la metodología, una vez realizada la prueba de validación del instrumento, sólo quedó un ítem para fórmula de cortesía. Dado que este número es excesivamente bajo, no pudo ser considerado en la comparación de comprensión de acuerdo al tipo de enunciado, y el contraste se realizó entre contrafactuales, hipérboles y preguntas.

La tabla 5 con las medias generales especifica las diferencias de acuerdo al tipo de enunciado implicado en el nivel comprensivo de los participantes.

Tabla 5

Medias generales de acuerdo al tipo de enunciado

\begin{tabular}{|c|c|c|c|}
\hline Tipo de enunciado & Media & Desviación típica & $\begin{array}{c}\text { Error estándar } \\
\text { de la media }\end{array}$ \\
\hline Hipérbole & 1,50 & 0,99 & 0,031 \\
\hline Contrafactual & 1,81 & 0,97 & 0,031 \\
\hline Pregunta & 0,77 & 0,77 & 0,025 \\
\hline
\end{tabular}

Se observa que son los enunciados de pregunta los más difíciles de comprender (aún más si los estudiantes son menores), resultan más accesibles los de hipérbole y dada la media estimada, los contrafactuales resultan ser los menos complejos para el colectivo encuestado.

Con el fin de determinar si las diferencias observadas en los estadísticos descriptivos no son producto de error, se aplicó la prueba no paramétrica de Friedman. La tabla 6 presenta los rangos y rangos medios para los tipos de enunciado.

Tabla 6

Rangos y rangos medios para los tipos de enunciado

\begin{tabular}{|c|c|c|}
\hline Tipos & Suma de rangos & Rango medio \\
\hline Hipérbole & 2099,5 & 2,13 \\
\hline Contrafactual & 2431,5 & 2,47 \\
\hline Preguntas & 1367,0 & 1,39 \\
\hline
\end{tabular}

Los resultados denotaron que todos los tipos de enunciados difieren significativamente entre sí $\left(\mathrm{X}_{\mathrm{gl}}^{2}\right.$ $=2=828,6, \mathrm{p}<0,0001)$, lo que nos permite corroborar lo anteriormente señalado.

\section{DISCUSIÓN}

Si se considera la relación edad de los sujetos y capacidad de comprender ironías, los resultados no sorprenden: a medida que se incrementa la edad, aumenta dicha capacidad. ¿No es esto una verdad de Perogrullo? En parte sí y en parte no. Si bien es lógico esperar que una habilidad mejore a medida que un niño va creciendo, los resultados comprueban que esto ocurre durante la edad escolar y no antes. En este sentido, puede decirse que la ironía es, como lo señala Nippold (1998), un fenómeno de adquisición tardía del lenguaje oral.

Ya se hizo referencia, en apartados anteriores, a las diferencias de opinión de los diversos autores respecto a la edad en que se comienza a comprender la ironía. Tal vez, esta diversidad obedezca a las 
diferencias de método y a la diversidad del fenómeno irónico señaladas tanto por Creusere (1999) como por Nakassis y Snedeker (2002). Aquí se agregaría la idea de que la capacidad de comprender ironías no es un fenómeno de todo o nada, es decir, los niños no adquieren la capacidad de entender todos los enunciados irónicos íntegramente de una edad determinada a otra. Los datos en los cuales se muestran cuatro grupos de edad diferentes $(5-7,8-9,10-11,12-14)$, entre los que se observan diferencias estadísticamente significativas con respecto al nivel de comprensión, parecen representarnos una habilidad de lento desarrollo. Entonces, más que hablar de períodos y edades críticas bien diferenciadas, a partir de las cuales tenemos un comprendedor idóneo de la ironía, habría que referirse -basándose en la propuesta de Levorato y Cacciari $(1992,1995)$ y en el sentido planteado inicialmente por KarmiloffSmith (1992) - a fases de desarrollo que se solapan unas con otras y a través de las cuales el niño debe lidiar con un fenómeno multiforme, tanto desde el punto de vista lingüístico como contextual.

Por otra parte, si se considera el tipo de enunciado, se observa que éste sí influencia de manera significativa el grado de dificultad de la comprensión; en este sentido, los más fáciles de comprender son los enunciados contrafactuales. Ellos representan la forma más típica de la ironía y son aquellos en los cuales realmente lo que se dice es lo contrario de lo que se quiere decir o se espera sea dicho en un contexto determinado. En este sentido, su contenido ecoico es evidente. Le siguen las ironías asociadas con metáforas e hipérboles y la explicación a su relativa facilidad de comprensión estaría dada especialmente en el caso de la hipérbole-, porque el efecto de contraste que produce es muy similar al de la ironía (Colston \& O’Brien 2000) y, por tanto, podría ser un indicio que favoreciera su reconocimiento e interpretación.

Finalmente, son las preguntas irónicas las más difíciles de comprender para los niños. Tal vez esto se deba a que se confunden con los actos de habla indirectos (Searle 1993), en particular con las preguntas que suelen funcionar como "peticiones indirectas" (Escandell 1988; Belinchón, 1999). Dichos actos de habla son muy comunes en la lengua y los niños los empiezan a interpretar y a utilizar de manera adecuada alrededor de los 4 y 5 años (Owens 2003). Por esto, cuando los escolares se enfrentan a preguntas que no son literales, tal vez ignoren la contradicción con los elementos contextuales y prefieran esta interpretación más asequible.

A partir de estos últimos datos, el desarrollo de la comprensión irónica se nos presenta como un paso de lo más prototípico, ecoico y contrastivo a lo menos prototípico, caracterizado porque lo ecoico y lo contrastivo adquieren valores más sutiles.

Para concluir, es necesario señalar, por un lado, las limitaciones del trabajo y, por otro, las posibles interrogantes que cabe plantear. Una posible limitación estaría en que la diversidad y el número de tipos de enunciados fueron reducidos. En otros estudios, sería necesario ver qué ocurre con la adquisición de formas como las aseveraciones verdaderas que refieren Kumon-Nakamura et al. (1995). Respecto a los interrogantes, interesa indagar cómo interactúa esta nueva habilidad, que el escolar desarrolla, con la adquisición de la lengua escrita que ocurre en el mismo momento temporal. ¿Existe la posibilidad de que ambas habilidades se influyan entre sí o que necesiten una misma capacidad que las funde como la teoría de la mente? Investigaciones futuras tendrán que dar respuesta a esta interrogante.

\section{OBRAS CITADAS}

Ackerman, Bruce. 1986. “Children's Sensitivity to Comprehension Failure in Interpreting a Non-literal Use of an Utterance". Child Development 57: 458-497.

Anolli, Luigi, María Infantino y Rita Ciceri. 2001. "You're a Real Genius!". "Irony as a Miscommunication Design". Say not to Say: New Perspectives on miscommunication. Ed(s). Luigi Anolli, Rita Ciceri y Giuseppe. Riva. IOS Press. 142-160.

Astington, Janet. 1991. "Intention in the Child's Theory of Mind". Children's Theories of Mind: Mental States and Social Understanding. Ed(s). Douglas Frye y Chris Moore. Hillsdale, NJ: Erlbaum.

Bedoya, Angel. 1997. “¿Qué es la interactividad?”, 25 de febrero, 2003, http://www.sinpapel.com/art001.shtml

Belinchón, Mercedes. 1999. "Lenguaje no literal y aspectos pragmáticos de la comprensión". Psicolingüística del español. Ed(s). Manuel de Vega y Fernando Cuetos. Madrid: Editorial Trotta, S. A. 307-373.

Belinchón, Mercedes, Angel Rivière y José Manuel Igoa. 1992. Psicología del lenguaje. Investigación y teoría. Madrid: Trotta.

Cáceres, Pablo. 2005. “Análisis psicométrico del test de inferencias lingüísticas IMIP”. (Informe interno Proyecto FONDECYT N ${ }^{\circ}$ 1040740).

Cáceres, Pablo y Nina Crespo. 2006. "Análisis de la dimensionalidad de la escala de Inferencia Lingüística IMIP aplicando un modelo no paramétrico de Teoría de Respuesta al Item”. (en proceso). 
Capelli, Carol, Noreen Nakagawa y Carl Madden. 1990. "How children understand sarcasm: the role of context and intonation". Child Development 61: 1824-1841.

Chomsky, Noam. 1998. Nuestro conocimiento del lenguaje humano. Santiago: Impresos Universitaria, S. A.

Clark, Herbert y Richard Gerrig. 1984. "On the pretense theory of irony". Journal of Experimental Psychology: General 113: 121-126.

Clark, Herbert. 1996. Using language. Cambridge: Cambridge University Press.

Colston, Herbert y Jennifer O'Brien. 2000. "Contrast of Kind versus Contrast of Magnitude: The Pragmatic Accomplishments of Irony and Hiperbole". Discourse Processes 2. 30: 179-199.

Colston, Herbert. 2002. "Contrast and assimilation in verbal irony". Journal of Pragmatics 34: 111-142.

Creusere, Marlena. 2000. “A Developmental Test of Theoretical Perspectives on the Understanding of Verbal Irony: Children's Recognition of Allusion and Pragmaic Insincerity”. Metaphor and Symbol 15: 29-45.

- 1999. "Theories of Adults' Understanding and Use of Irony and Sarcasm: Applications to and Evidence from Research with Children". Developmental Review 19: 213-262.

Demorest, Ami et al. 1983. “Telling It as It Isn't: Children's Understanding of Figurative Language”. British Journal of Developmental Psychology 1: 121-134.

Dews, Shelley et al. 1996. "Children's Understanding of the Meaning and Functions of Verbal Irony". Child Development 67: 3071-3085.

Escandell, María Victoria. 1998. "Cortesía y Relevancia”. La Pragmática lingüística del español: Recientes desarrollos. Ed(s). Henk Haverkate, Gijs Mulder y Carolina Fraile Maldonado. Amsterdam: Ropodi. 131-146.

Giora, Rachel. 2003. Agosto 17. "Recent Trends in Literal vs. Figurative Language Research: The Case of Irony". Speech Pathology http://www. Speechpathology.com /articles /arc_disp.asp? article_id=51\&catit=491

_. 1995. "On irony and Negation". Discourse Processes 19: 239-264.

Grice, Herbert. 1975. "Logic and Conversation". Syntax and Semantics: Speech Acts. Ed(s). Jennifer Cole y Jerry L. Morgan. Nueva York: Academic Press vol. 3: 41-58.

Happe, Francesca. 1993. "Communicative Competence and Theory of Mind in Autism: A Test of Relevance Theory”. Cognition 48: 101-119.

Jorgensen, Julia, George Miller y Dan Sperber. 1984. Test of the mention theory of irony. Journal of Experimental Psychology: General 113: 112-20.

Karmiloff-Smith, Annette. 1992. Más allá de la modularidad de la mente. Madrid: Alianza.

Keenan, Thomas y Kathleen Quigley. 1999. Do Young Children Use Echoic Information in Their Comprehension of Sarcastic Speech? A Test of Echoic Mention Theory. British Journal of Developmental Psychology 1.17: 8314.

Kreuz, Roger y Sam Glucksberg. 1989. How to Be Sarcastic: The Echoic Reminder Theory of Verbal Irony. Journal of Experimental Psychology: General 118: 374-386.

Kumon-Nakamura, Sachi, Sam Gluksberg y Mary Brown. 1995. How about another Piece of Pie: The Allusional Pretense Theory of Discourse Irony. Journal of Experimental Psychology: General 124: 3-21.

Levorato, Maria Chiara y Cristina Cacciari. 1995. The Effects of Different Ttasks on the Comprehension and Production of Idioms of Children. Journal of Experimental Child Psychology 60: 261-283.

- 1992. Children's Comprehension and Production of Idioms: The Role of Context and Familiarity. Journal of Chld Language 19: 415-433.

Levorato, Maria Chiara, Barbara Nesi y Cristina Cacciari. 2005. Reading Comprehension and Understanding Idioms Expression: A Developmental Study. Brain and language. (en proceso).

Nakassis, Constantibe y Jesse Snedeker. 2002. "Beyond Sarcasm: Intonation and Context as Relational Cues in Childrens's Reconigtion of Irony". Procedings of the Tweenty-sixth Boston University Conference on Language Development. [Versión electrónica]. Ed(s). A. Greenhyll, M. Hughs, H. Little Field, y H. Walsh. Summerville, MA: Cascadilla Press.

Nippold, Marilyn. 1998. Later Language Development. The School Age and Adolescent Years. Austin: Proed.

Owens, Robert. 2003. Desarrollo del lenguaje. Madrid: Pearson Educación.

Padilla, José Antonio. 2005. "Enunciados irónicos en español: Estudio fonopragmático". (en proceso).

Ruiz, Leonor et al. 2004. "El proyecto GRIALE para la ironía en español: Conceptos previos". Revista de Lengua Española y Lingüística General 18: 231-242.

Searle, John. 1993. "Metaphor". Metaphor and Thought. Ed. A. Ortony Cambridge: Cambridge University Press. 83-111.

Sijtsma, Klaas e Ivo Molenaar. 2002. Introduction to Non-parametric Item Response Theory. California: Sage Publication.

Sperber, Dan. 1984. "Verbal Irony: Pretense or Echoic Mention?” Journal of Experimental Psychology: General 113: $130-136$ 
Sperber, Dan y Deirdre Wilson. 1998. "Irony and Relevance: A Reply to Drs. Seto, Hamamoto and Yamanashi". Relevance Theory: Applications and Implications. Ed(s). Robyn Carston y Seiji Uchida. Amsterdam: John Benjamins. 283-293

Sullivan, Kate, Ellen Winner y Natalie Hopfield. 1995. "How Children Tell a Lie from a Joke: The Role of SecondOrder Mental State Attributions". British Journal of Developmental Psychology 13: 191-204.

Wimmer, Heinz y Joseph Perner. 1983. "Beliefs about Beliefs: Representation and Constraining Function of Wrong Beliefs in Young Children's Understanding of Deception”. Cognition 13: 103-128.

Winner, Ellen y Susan Leekam. 1991. "Distinguishing Irony from Deception: Understanding the Speaker's SecondOrder Intention”. British Journal of Developmental Psychology 9: 257-270.

\section{ANEXO I}

\section{EJEMPLOS DE IRONIAS Y ALTERNATIVAS DE RESPUESTA - INSTRUMENTO IMIP}

1. José llega tarde a clases, la profesora le dice: "Un poco más y llega a la hora de salida".

José se pregunta: ¿Qué quiere decir la profesora?

a) Que llegué a la salida (interpretación literal).

b) Que llegué muy atrasado (interpretación adecuada).

c) Que me acerque un poco más (distractor).

7. José ha jugado mal al fútbol pero aun así le corrige a su amigo El Guatón. Este se pone colorado y enojado le dice: "iMiren al gran futbolista!”.

José se pregunta: ¿Qué me quiere decir?

a) Que sea parte del equipo (distractor).

b) Que soy un gran futbolista (interpretación literal).

c) Que no soy un gran futbolista (interpretación adecuada).

10. Fernando se toma toda la bebida de José y éste -señalando la botella vacía- le dice: “¿No quieres un poco más?".

Fernando se pregunta: ¿Qué quiere decir José?

a) Me ofrece más bebida (interpretación literal de la petición).

b) Se burla porque me he tomado toda la bebida (interpretación adecuada).

c) Dice que no quiere más bebida (distractor). 